\title{
COMUNICAÇÃO
}

\section{ALTERAÇÕES ÓSSEAS OBSERVADAS NA LEISHMANIOSE CUTÂNEA DIFUSA (LCD) NO ESTADO DO MARANHÃO}

\author{
Ana Cristina R. Saldanha, Tatiana S. Malheiros, Cyntia da Conceição R. Rodrigues, \\ Ivelise Theresa A. Balby e Jackson M.L. Costa
}

Considerada condrófila, acometendo sobretudo a porção anterior do tabique nașal, a leishmaniose tegumentar americana (LTA) ou cutâneo-mucosa, costuma poupar o plano ósseo, sendo este um aspecto pouco discutido na literatura ${ }^{361112}$. Estudos de Pupo $^{10}$ em 1946 e Barros ${ }^{3}$ em 1952 relataramque as alterações radiológicas na LTA, podem apresentar-se como um espessamento eburnizante com bosseladuras nas diáfises de ossos longos, bem como focos discretos de destruição óssea, outras vezes hipertrofia periostal, apresentando-se os ossos longos bosselados e com freqüentes encurvações.

Guimarães e cols ${ }^{6}$ em 1957, descreveram um caso de LTA, onde puderam constatar a presença de alterações ósseas em sítios isentos de lesões cutâneas circunjacentes, sugerindo a hipótese de origem hematogênica das mesmas.

Arias Aranda e cols ${ }^{12}$ na Argentina fizeram a primeira referência à espina ventosa leishmaniótica, após a descrição de dois pacientes que apresentavam alteraçôes compatíveis com processos de osteomielite crônica rarefaciante e osteíte crônica condensante em localizações correlacionadas a lesões cutâneas leishmanióticas.

No Maranhão a LTA, possui comportamento endêmico na maioria de seus municípios, não havendo, entretanto, até o presente momento relato de comprometimento ósseo. Tal aspecto pode ser observado por nossa equipe em apenas dois pacientes portadores de leishmaniose cutânea difusa (LCD), causado por Leishmania amazonensis, cujo aspecto clínico caracteriza-se por apresentar curso crônico, acometendo extensas áreas da superfície corporal, caráter deformante e presença de polimorfismo lesional, algumas vezes assemelhando-se a hanseniase virchowiana ${ }^{412}$. Nos dois casos (pacientes

\footnotetext{
Departamento de Patologia da Universidade Federal do Maranhão, Sāo Luís, MA, Brasil.

Endereço para correspondência: Prof. Jackson Mauricio Lopes Costa. Depto. de Patologia/UFMA. Praça Madre Deus 2, 65025-560 São Luís, MA. Fax: (098) 222-5135

Recebido para publicação em 21/06/94.
}

R.N.P.S. e R.F.O.) observou-se lesões cicatriciais atróficas, pregueadas, hipo e hipercrômicas, disseminadas pelo corpo cuja localização a nível das extremidades foram responsáveis pelo aspecto deformante e limitação de movimentos dos quirodáctilos e pododáctilos, havendo inclusive perda de falange distal em $2^{\circ}$ pododáctilo direito de um dos pacientes (RFO). As alterações radiológicas observadas mostram: desmineralização óssea difusa, afilamento das falanges médias e distais, com redução dos espaços interfalangeanos mediais (Figura $1 \mathrm{e}$ 2).

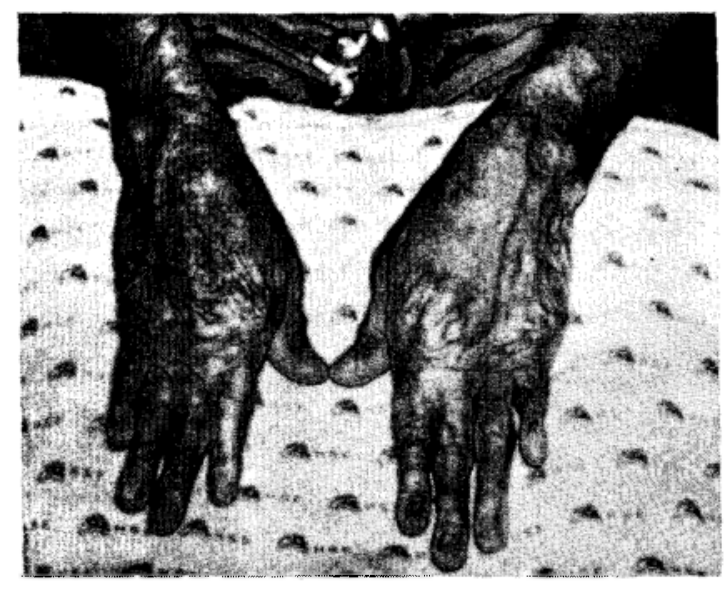

Figura 1 - Paciente R.F.O., mostrando detalhes das mãos com extensas cicatrizes atróficas, pregueadas, associadas a deformaçöes dos quirodáctilos dificultando os movimentos dos mesmos.

Os mecanismos fisiopatogênicos responsáveis por tais alterações permanecem obscuros, havendo entretanto a hipótese de que estas lesões possam ser secundárias a fibrose da pele e partes moles. $\mathrm{Na}$ LCD a reabsorção óssea, tem sido relacionada a intensa proliferação fibroblástica com acentuada retração cicatricial e determinação de uma espécie de encarceramento local, diferindo da leishmaniose 
Comunicaçao. Saldanha ACR, Malheiros TS, Rodrigues CCR, Balby ITA, Costa JML. Alterações ósseas observadas na leishmaniose cutanea difusa (LCD) no Estado do Maranhão. Revista da Sociedade Brasileira de Medicina Tropical 28:55-56, jan-mar, 1995.

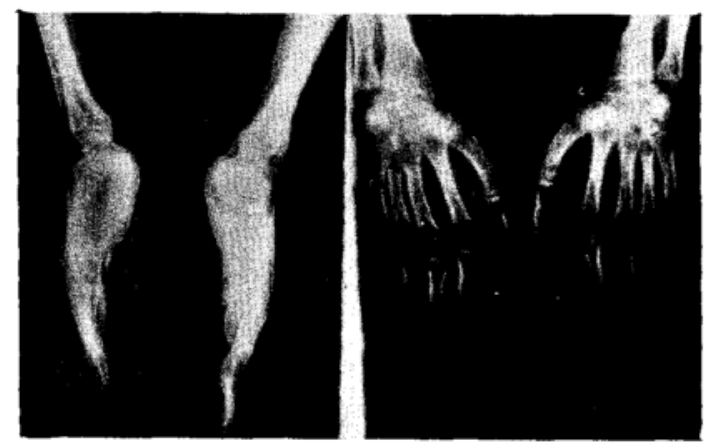

Figura 2 - Alterações radiológicas no paciente (R.F.O.), desmineralização óssea difusa, afilamento das falanges, mediais e distais, com redução dos espaços interfalangeanos.

cutâneo-mucosa que pode determinar lesões ósseas por ação direta do parasita ${ }^{3} 679$. Barros e cols ${ }^{3}$, referem que tais lesões possam ser devidas a processos inflamatórios outros ou a lesões específicas da mucosa adjacente. A associação.entre o processo infeccioso cutâneo e a destruição óssea é ainda defendida por Medina e cols ${ }^{8}$.

Tais mecanismos, seriam insuficientes para justificar a ocorrência de acometimento ósseo em regiões onde inexiste lesão cutânea, ulcerada ou cicatricial, como no caso descrito por Oswaldo Costa $^{5}, 1953$, no qual o autor detectou a presença de Leishmania braziliensis no material obtido a partir de punção da articulação que apresentava clinicamente tumefação e dor, radiologicamente demonstrava processo de periostite, podendo reforçar a hipótese de origem hematogênica da lesão óssea, defendida por Guimarães ${ }^{6}$.

Pode-se concluir, portanto, que o comprometimento ósseo deva ser um aspecto considerado entre as possíveis manifestações clínicas da LTA, inclusive na sua forma difusa, havendo necessidade de estudos direcionados visando determinar a natureza da lesão como manifestação primária ou secundária da doença.

\section{REFERÊNCIAS BIBLIOGRÁFICAS}

1. Arias Aranda C. Foco familiar de leishmaniasis tegumentar americana. $5^{\mathrm{a}}$ Reunion de La Sociedad Argentina de Patologia Regional del Norte 1:590594, 1930.

2. Arias Aranda C, Rosa A. Existem localizaciones óseas en la leishmaniasis americana?. $6^{\mathrm{a}}$ Reunion de La Sociedad Argentina de Patologia Regional del Norte 2:460, 1931.

3. Barros RF, Lima MLT, Correa A. Alterações sinusais na Leishmaniose nasal com estudo radiográfico e histopatológico. Revista das Clínicas da Faculdade de Medicina da Universidade de São Paulo 7:145-150, 1952.

4. Costa JML, Saldanha ACR, Mello e Silva AC, Serra-Neto A, Galvão CES, Pedroso e Silva CM, Silva AR. Estado atual da Leishmaniose cutânea difusa (LCD) no Estado do Maranhão II. Aspectos epidemiológicos, clínicos e evolutivos. Revista da Sociedade Brasileira de Medicina Tropical 25:115$123,1992$.

5. Costa OG, Dactilitis Leishmaniótica Archives Argentinos de Dermatologia 3:149-153, 1953.
6. Guimarães $N$, Silva YP. Lesōes ósseas da leishmaniose. Anais Brasileiros de Dermatologia e Sifilografia 32:5-7, 1957.

7. Kochs AG. Sulla participazione ossea nella leishmaniase cutanea. Minerva Dermatologia $99: 455$ 458, 1969.

8. Medina R, Lizardo C. Leishmaniasis de la orega Dermatologia Venezuelana 2:54-57, 1960.

9. Pessoa SB, Barreto MP. Leishmaniose Tegumentar Americana. Imprensa Nacional, Rio de Janeiro. 1948.

10. Pupo JA. Estudo Clínico da Leishmaniose Tegumentar Americana. Revista do Hospital das Clínicas da Faculdade de Medicina da Universidade de São Paulo 1:113, 1946.

11. Rodriguez LV, Uzquiano FC, Desjeux P, Valle SWC. Leishmaniose cutânea recidivante com alterações ósseas. Relato de um caso. Anais Brasileiros de Dermatologia 63:31-34, 1988.

12. Silva D. Leishmaniose tegumentar queloidiana, comlesões ósseas. Anais Brasileiros de Dermatologia e Sifilografia 33:3-7, 1958. 